\title{
COVID-19: Comparison of Epidemiological Measures-State of Emergency vs Social Distance
}

\author{
Danijela Cvetković ${ }^{1}$, Aleksandar Cvetković ${ }^{2}$, Milena Milutinovic ${ }^{3}$, Danijela Nikodijević ${ }^{3}$, \\ Jovana Jovankić ${ }^{3}$, and Nenad Filipovic ${ }^{4}$ \\ ${ }^{1}$ University of Kragujevac \\ ${ }^{2}$ University of Kragujevac Faculty of Medicine \\ ${ }^{3}$ University of Kragujevac Faculty of Science and Mathematics \\ ${ }^{4}$ University of Kragujevac Faculty of Mechanical Engineering
}

June 25, 2020

\begin{abstract}
Background: By interrupting all human-to-human transmission, SARS and MERS were effectively eradicated few years ago, but, due to the numerous asymptomatic cases of COVID-19, spreading of disease is facilitated and it will be difficult to overcome it in this way. Methodology: The aim of our study was to compare the efficacy and consequences of proposed epidemiological measures between countries. We analyzed the available databases to compare states with strict whit those with relatively liberal approach to COVID-19 prevention. Results: We showed a statistically significant difference in the number of patients and deaths caused by SARS-CoV-2 depending on the degree and timing of the epidemiological measures introduced in studied countries. Conclusion: Apart from the characteristics of the virus itself, the epidemiological measures that have been introduced, as well as their timing, are essential for preventing the spread of COVID 19 infection. In the absence of an effective drug or vaccine traditional epidemiological measures are the only weapon in the battle against COVID-19.
\end{abstract}

\section{BACKGROUND}

Wuhan was registered on December 19, 2019 as the epicenter of the emergence of a new virus from the group of coronaviruses that showed the characteristics of interhuman transmission, causing a respiratory disease presenting with fever, dry cough, and often severe pneumonia with ARDS [1]. The World Health Organization (WHO) announced the pandemic disease (COVID-19) caused by SARS-CoV-2 and brought measures in order to interrupt spread of SARS-CoV-2 worldwide. Currently, COVID-19 has spread widely around the world, affecting more than 6,343,188 people around the world with more than 376,290 deaths caused by virus [2]. The presence of coronavirus viruses that circulate in nature and cause diseases in humans is not new, but so far these were mainly the types of viruses responsible for seasonal colds. The epidemics caused by viruses from this group SARS 2002-03 and MERS 2012 are still in the relatively fresh memory of most people when they caused great fear, but were soon overcome despite the lack of causal treatment or vaccine, and thanks to strict epidemiological measures. All these infections, since they are caused by viruses from the same group, have a similar clinical picture and ways of transmission, although over time it turned out that they have significant differences. SARS and MERS showed significantly higher mortality, with 8096 cases and 774 deaths in 29 countries from SARS, accounting for 9.6\%; and 2,494 MERS patients with 858 deaths in 27 countries, accounting for $34.4 \%$ [3]. In all cases, the droplet route of transmission of the infection was dominant, although there was also the fecal route, so close contact was necessary in order 
to achieve interhuman transmission. Although mortality in SARS and MERS was far higher, SARS-CoV-2 has a significantly higher number of deaths in proportion to the higher number of patients [4].

The conversion enzyme Angiotensin 2, found in the lower respiratory tract in humans, is a target site for COVID 19 virus binding, so it is not surprising that respiratory symptomatology is dominant, even with the development of Acute Respiratory Distress Syndrome (ARDS), which is life-threatening clinical condition. Overall incubation period was approximately 5 days, and during this period patient is also infective [5]. The course of the disease in patients with severe clinical picture is such that on average in 8-20 days ARDS develops with the need for mechanical ventilation, while the findings on MSCT lungs are most pronounced after 10 days and sometimes in serologically negative patients the characteristic findings on the lungs are sufficient to make a diagnosis [1] [6] [7]. The beginning of the epidemic in Wuhan was covered by the media, but it seems that many European countries did not take the new fact seriously enough and believed that it was a disease no more dangerous than the flu, which is also quite far away. China, with a huge burden of this disease, has taken strong measures to control the spread and improve the curative rate of COVID-19 [3]. Other states, primarily in Europe, introduced epidemiological measures with the aim of preventing the spread of infection, which ranged from closing entire cities and municipalities, introducing a state of emergency with police and military engagement to liberal recommendations on social distance as seen in Sweden.

In this paper, we summarized the epidemiological characteristics, number of cases and number of deaths from COVID-19 taking into account different epidemiological measures [8, 9]. A comprehensive understanding of these measurement effectiveness would improve control the disease. The aim of our study was to compare the efficacy and consequences of proposed epidemiological measures between countries.

\section{MATERIAL AND METHODS}

We tried to analyze the available databases to compare the different levels of epidemiological measures and their consequences on the spread of COVID 19 infection. From the relevant sources, we have singled out data for China, as an example of the most rigorous measures to prevent the spread of disease, through moderate models that were predominantly represented in USA and Europe (Serbia, Croatia, France, United Kingdom, Germany, Italy, Spain) to isolated, liberal approach, as seen in Sweden. We searched Pub Med for articles published from 1-4-2020, using the key words " coronavirus", "COVID-19", "SARS-CoV-2", "social distance", "incubation period", moreover, we consulted the web pages of organizations such as WHO, European Centre for Disease Prevention and Control, Worldometer, as well as publicly available data on the websites of the Ministries of the studied countries [10, 11, 12].

\section{STATISTICAL ANALYSIS}

Significance was determined using the one-way ANOVA followed by a post-hoc Tukey's significant difference (HSD) test. A $p$ value $<0.01$ was considered as significant. The magnitude of correlation between variables was done using SPSS (Chicago, IL) statistical software package (SPSS for Windows, ver. 17, 2008).

\section{RESULTS}

Most of the surveyed countries introduced some kind of epidemiological measures immediately after the sudden increase in the number of patients. We have tried to present a clear trend in the increase in the number of patients and deaths in the light of the measures taken, which differed between countries, ranging from strict restrictions on movement and quarantine within the state of emergency, such as the drastic example of China, to somewhat "softer" measures introduced in most European countries to measures taken by Sweden government, which included recommendations on the behavior of the population and the closure of less important economic activities, secondary schools and colleges, but even not the suspension of work 
in primary schools and kindergartens. There are countries that have locked entire cities and areas, but the question is whether such measures were adopted in a timely manner and properly implemented. All studied countries have been compared with Sweden, as an example of liberal approach to COVID-19 prevention.

Graph 1. COVID-19 deaths per one million of population for 11 studied states during the period 2020-03-11 to $2020-05-31$.

The data were taken from the address: https://www.ecdc.europa.eu/en/publications-data/download-todaysdata-geographic-distribution-covid-19-cases-worldwide) [11].

Graph 1 shows mortality from SARS-CoV-2 infection. We monitored mortality in the period from the introduction of the pandemic on March 11, 2020 by the WHO to May 31, 2020. The leading countries in terms of the number of deaths due to SARS-CoV-2 infection are clearly observed.

Graph 2. Total cases per one million of population during the period 2020-03-11 to 2020-05-31.

The results are presented as mean \pm standard error of the mean. A p value $<0.01$ was considered as significant.

A one-way ANOVA followed by a post-hoc Tukey's significant difference (HSD) test was performed to determine the statistical significance in the number of confirmed COVID-19 cases between the examined countries in relation to Sweden. A statistically significant difference was observed (Graph 2) in the period since the introduction of the pandemic on March 11, 2020 by the WHO until May 31, 2020. A statistically significantly lower number of newly diagnosed cases is present in countries that have introduced strict quarantine compared to Sweden with somewhat more flexible protection measures against SARS-CoV-2 infection. On the other hand, the data also show a statistically significant increase in new infections in Italy, USA and Spain compared to Sweden.

Graph 3. Total deaths per one million of population during the period 2020-03-11 to 2020-05-31.

The results are presented as mean + - standard error of the mean. A p value $<0.01$ was considered as significant.

Graph 3 shows the total death rate from Covid-19 per million population in the period 2020-03-11 to 2020-053 . The results showed a statistically significantly lower mortality in countries with a strict epidemiological regime (Serbia, China, Norway, Germany and Croatia) compared to Sweden. The results also show a significantly high mortality rate from this disease in Italy, Spain and the UK compared to Sweden.

Graph 4. Comparison of new cases per one million of population between studied countries and Sweden.

A comparison of new cases per million COVID 19 between the surveyed countries with Sweden is shown in Graph 4. The largest differences in the number of new cases are observed in the comparison of Sweden and Croatia, Serbia, China, Germany and Norway, respectively.

\section{DISCUSSION}

The COVID 19 pandemic showed quite unexpected results considering the level of health care systems, organization and the economic power of different states, so many states that considered their health system to be quite well organized experienced such a sharp increase in seriously ill patients so their health systems became overloaded and could not meet the needs of the population. It is very valuable to objectively study the factors that led to this consequence, concerning the health systems themselves or, more likely, the epidemiological measures implemented by the state apparatus. In the media, one could often hear at least doubts about the pandemic response that Sweden implemented, as very liberal and unjustifiably optimistic, to condemn the drastic measures seen in China, which allegedly concerned unnecessary and as inappropriate restriction of personal freedoms. Besides the level of the introduced measures, there is also the question of their timeliness. Scientists were aware that without causal treatment and in the absence of a vaccine, the 
spread of the infection could not be prevented, but measures were prescribed as a national epidemiological priority, which should have as a goal a "flattened curve" of the spread of the disease in order to prevent such a rapid spread of disease that could lead to overloading of national health systems and their collapse [14].

China has imposed a state of emergency with significant military and police engagement, so by January 29, the entire province of Hubei was in isolation [14]. It was a period when Europe and the USA observed the situation and hoped that the epidemic would remain at the local level and soon be overcome as SARS 2003, but unfortunately, very important differences between SARS Cov and SARS Cov 2 were not known. In many ways, Wuhan had a predisposition for further spread of the infection. It is a very large city with over 11 million inhabitants, with the largest airport and railway station, important industrial plant, with traffic that has multiplied in previous years while population density has even tripled in the last decade. Also, the spread of the infection was favored by a large celebration of the lunar New Year just before the introduction of epidemiological measures. Infection was disseminated despite enormous efforts and strict epidemiological measures that were introduced relatively quickly [15].

On January 31, the Italian government suspended air traffic with China as a known source of infection, and then in early February, 11 municipalities in the northern part of the country were quarantined. Soon quarantine extended to the entire country, with the suspension of all industries that are not essentia [16]. On February 24, there was a sharp increase in the number of patients reaching a peak within 20 days with about 6,000 patients in one day [17]. The Spanish government started a series of epidemiological measures on March 14, with the suspension of all non-essential activities. It is important to mention that before the beginning of what soon became known as the "Italian and Spanish scenario", a big football match, which can be characterized as an epidemiological incident, was played between the Italian and Spanish rivals with about 40,000 spectators in the region that soon became the epicenter of the infection [18]. This is a probable reason and explanation why there was a significantly higher number of patients and deaths in Italy and Spain compared to Sweden.

France introduced a state of emergency on March 17, but the first round of municipal elections was held in France on March 15, which certainly had an impact on the further course of the epidemic in the country $[19,20]$. USA declared a state of emergency on March 13. The increase in the number of patients was quite large and sudden, so even an economic power such as the USA soon faced the situation that there was not enough medical equipment, hospital facilities, personal protective equipment, as well as tests, despite mass production and reorientation of certain industries on production of medical supplies. Comparing the number of patients and deaths from COVID-19 infection in Sweden and the USA, we concluded that the difference in the number of patients is statistically significant, but not mortality [11].

The state of emergency was introduced in Serbia on March 17, with movement bans for people over 60 (65) years of age [21]. Strict restraint measures were also strictly implemented for persons under house observation and quarantine. Compared to Sweden, there were statistically significantly fewer patients and deaths from COVID-19 infection in Serbia, in spite of over 30,000 temporary workers abroad who returned to Serbia at the very beginning of the epidemic.

In United Kingdom, On March 23, a state of emergency is imposed, with the suspension of many industries, economic disciplines, gathering places, while the population is banned from "irrelevant" travel and contacts except with family members. Social distance was ordered and the broad permission were given to police to implement epidemiological measures [11].

Germany is a country with a traditionally strong health system. Upon arrival of the first cases, moderate epidemiological measures are recommended. On March 13, measures, which included closing schools and kindergartens, stopping higher education and banning visits to nursing homes because it was already known that the elderly population is more susceptible to severe clinical picture if they become ill. Shortly afterwards, the borders with the surrounding countries were closed, and within Germany some areas introduced different levels of epidemiological measures with a state of emergency, while others introduced strict social distance [22]. Croatia On March 24 introduced very strict measures to control the infection, which, together with 
the early detection of the trajectory of the infection, good information and cooperation of the population, led to a very good control of the disease $[23,24]$. Sweden is a country that has introduced a fairly liberal system of epidemiological measures relying on the health education of the population. Recommendation of the Public Health Agency were continuation of the work of primary schools, avoiding of trips that are not necessary, to work remotely, not to gather more than 50 people, respecting physical distance and for people over the age of 70 to stay at home as long as possible. Swedish government considered that well-informed and motivated persons understand and follow the given recommendations, and that personal responsibility is better than coercive measures. For people with symptoms suspicious of COVID-19, the advice was to stay at home. Thus, they soon reached the level of $30 \%$ fewer vehicles and $70 \%$ of pedestrians active in Stockholm, and that over $50 \%$ of classes take place at a distance. It was also believed that in this way a wider "controlled infection" of the population will be achieved in order to acquire collective immunity [25]. Norway is a country that is very similar to Sweden in size, population, geographical position and mentality. Unlike Sweden, Norway has introduced a number of much stricter epidemiological measures, and the results indicate that Norway has a lower incidence rate and a significantly lower number of deaths from COVID-19 infection [26].

Unfortunately, as in previous cases with SARS and MERS, we do not have an antiviral drug or vaccine, so classic epidemiological measures such as active detection and isolation of cases, tracking infection, quarantine, social distance and hygiene measures are the only weapons to combat COVID-19. Although our experiences from the SARS and MERS epidemics are very important, it is essential to understand that there are also very important differences [4]. In addition to the economic strength and quality of the health care system in each country, a very important factor is represented by social events, the way of behaving the population, epidemiological measures implemented by the state apparatus according to the advices of experts and also timing of all measures. There are several objective reasons that have contributed to the rapid and massive spread of the disease concerning the nature of the virus itself, such as the large number of asymptomatic or subclinical carriers of the virus, which was not common for SARS and MERS. Another possible cause would be the higher virulence of this virus compared to SARS and MERS, despite lower mortality. The third reason might be existence of different subtypes of the virus that have a somewhat different clinical picture and disease outcome. Also, there is a possibility that the virus experienced some kind of attenuation by passing through the human population. According to early reports from China, on February 11, 72,314 cases were registered with only $889(1 \%)$ asymptomatic carriers of the virus. Subsequent reports from Europe indicated that there were many more asymptomatic cases that posed the main epidemiological danger because the carrier is not aware of it at the time of infection, realizing multiple contacts and contributing to the rapid dispersal of the disease [3]. In addition to the reasons concerning the virus itself, the discipline of a nation and its government, as well as the introduction of appropriate epidemiological measures, which should be not only sufficient but also timely, also play an important role. In any case, until a vaccine or possibly an antiviral drug would be developed, we are left with only epidemiological protection measures, so the fight against COVID-19 will probably continue with occasional fluctuations, new outbreaks and residues of infection and conditions of new patterns of "normal" behavior in epidemiological terms.

\section{CONCLUSION}

Our data showed that in addition to the characteristics of the virus itself, the introduced epidemiological measures, as well as their timeliness, are important for preventing the spread of COVID infection 19. Mass events such as sports matches, elections, big celebrations and traveling, especially traffic between states can significantly determine the epidemiological course. It remains to be seen whether the liberal approach we have seen in Sweden is justified, whether there will be the emergence of collective immunity and how important it will be, considering opening of borders with countries that have not implemented the same epidemiological methods. Meantime we will have to adopt the new standards of "normal" life in coexistence with the virus with adequate epidemiological measures, at least until a vaccine or effective drug are found. 


\section{CONFLICT OF INTEREST}

The authors have declared that no competing interests exist.

\section{ACKNOWLEDGEMENTS}

The authors are grateful to the Ministry of Education, Science and Technological Development of the Republic of Serbia for financial support (Projects No. III41007).

\section{REFERENCES}

1. World Health Organization. Coronavirus disease (COVID-2019) situation reports https://www.who.int/emergencies/diseases/novel-coronavirus-2019/situation-reports. 2020.

2. Deng CX. The global battle against SARS-CoV-2 and COVID-19. Int J Biol Sci. 2020; 16(10):16761677. doi:10.7150/ijbs.45587. http://www.ijbs.com/v16p1676.htm.

3. Wu Z, McGoogan JM. Characteristics of and Important Lessons From the Coronavirus Disease 2019 (COVID-19) Outbreak in China: Summary of a Report of 72314 Cases From the Chinese Center for Disease Control and Prevention. JAMA. 2020;323(13):1239-1242. doi:10.1001/jama.2020.2648.

4. Wilder-Smith A, Chiew CJ, Lee VJ. Can we contain the COVID-19 outbreak with the same measures as for SARS? Lancet Infect Dis. 2020;20(5):e102-e107. doi: 10.1016/S1473-3099(20)30129-8

5. Holshue ML, DeBolt C, Lindquist S. First case of 2019 novel coronavirus in the United States. N Engl J Med. 2020 doi: 10.1056/NEJMoa2001191.

6. Pan F, Ye T, Sun P. Time course of lung changes on chest CT during recovery from 2019 novel coronavirus (COVID-19) pneumonia. Radiology. 2020: 295:3 https://doi.org/10.1148/radiol.2020200370

7. Bohmer M, Buchholz U, Corman V, et al. Outbreak of COVID-19 in Germany Resulting from a Single Travel-Associated Primary Case. The Lancet Infectious Diseases, 2020. https://doi.org/10.1016/S1473-3099(20)30314-5

8. Ge H, Wang X, Yuan X, et al. The epidemiology and clinical information about COVID-19. Eur J Clin Microbiol Infect Dis. 2020;39(6):1011-1019. doi: 10.1007/s10096-020-03874-z

9. World Health Organization, Coronavirus Disease (COVID-19) Dashboard. Available from: https://covid19.who.int/?gclid=EAIaIQobChMI_efurt_n6QIVluvtCh3lfgBwEAAYASAAEgKUCfD_BwE

10. European Centre for Disease Prevention and Control (ECDC). Geographical distribution of 2019nCov cases globally 2020 - 02 February 2020. Stockholm: ECDC. [Accessed 12 Feb 2020]. Available from: https://www.ecdc.europa.eu/en/geographical-distribution-2019-ncov-cases

11. Our World in Data (OWID): https://github.com/owid/covid-19-data/tree/master/public/data

12. Worldometer COVID-19 CORONAVIRUS PANDEMIC. 2020. https://www.worldometers.info/coronavirus/

13. Jin Y, Yang H, Ji W, et al. Virology, Epidemiology, Pathogenesis, and Control of COVID-19. Viruses. 2020;12(4):372. doi: 10.3390/v12040372

14. Ruan Q, Yang K, Wang W, et al. Clinical predictors of mortality due to COVID-19 based on an analysis of data of 150 patients from Wuhan, China. Intensive Care Med. 2020;46(5):846-848. doi:10.1007/s00134-020-05991-x.

15. Bogoch II, Watts A, Thomas-Bachli A. Potential for global spread of a novel coronavirus from China. J Travel Med. 2020; 27:2, March 2020 https://doi.org/10.1093/jtm/taaa011

16. Sjodin H, Wilder-Smith A, Osman S, Farooq Z, Rocklov J. Only strict quarantine measures can curb the coronavirus disease (COVID-19) outbreak in Italy, 2020. Euro Surveill. 2020;25(13):2000280. doi:10.2807/1560-7917.ES.2020.25.13.2000280.

17. Giordano, G., Blanchini, F., Bruno, R. et al. Modelling the COVID-19 epidemic and implementation of population-wide interventions in Italy. Nat Med (2020). https://doi.org/10.1038/s41591-020-0883-7.

18. Ceylan Z. Estimation of COVID-19 prevalence in Italy, Spain, and France. Sci Total Environ. 2020; 10;729:138817. doi:10.1016/j.scitotenv.2020.138817. 
19. Bernard Stoecklin S, Rolland P, Silue Y, et al. Investigation Team First cases of coronavirus disease 2019 (COVID-19) in France: surveillance, investigations and control measures, January 2020. Euro Surveill. 2020;25(6):2000094. doi:10.2807/1560-7917.ES.2020.25.6.2000094.

20. Spiteri G, Fielding J, Diercke M, et al. First cases of coronavirus disease 2019 (COVID-19) in the WHO European Region, 24 January to 21 February 2020. Euro Surveill. 2020;25(9):2000178. doi:10.2807/1560-7917.ES.2020.25.9.2000178.

21. Ministry of Health, Republic of Serbia. Covid 19. Available: https://covid19.rs/.

22. Rothe C Schunk M Sothmann P et al. Transmission of 2019-nCoV Infection from an asymptomatic contact in Germany. N Engl J Med. 2020; 382: 970-971. doi: 10.1056/NEJMc2001468

23. Čivljak R, Markotić A, Kuzman I.The third coronavirus epidemic in the third millennium: what's next? Croat Med J. 2020;61:1-4. 10.3325/cmj.2020.61.1.

24. HZJZ - Croatian Institute of Public Health. Koronavirus - najnoviji podatci. Available: https://www.hzjz.hr/priopcenja-mediji/koronavirus-najnoviji-podatci/. Accessed: 10 April 2020.

25. Gémes K, Talbäck M, Modig K, et al. Burden and prevalence of prognostic factors for severe COVID-19 in Sweden. Eur J Epidemiol. 2020;35(5):401-409. doi:10.1007/s10654-020-00646-z.

26. Jorstad OK, Moe MC, Eriksen K. Et al. Coronavirus disease 2019 (COVID-19) outbreak at the Department of Ophthalmology, Oslo University Hospital, Norway. Acta Ophthalmol, 2020;98: e388e389. doi:10.1111/aos.14426.

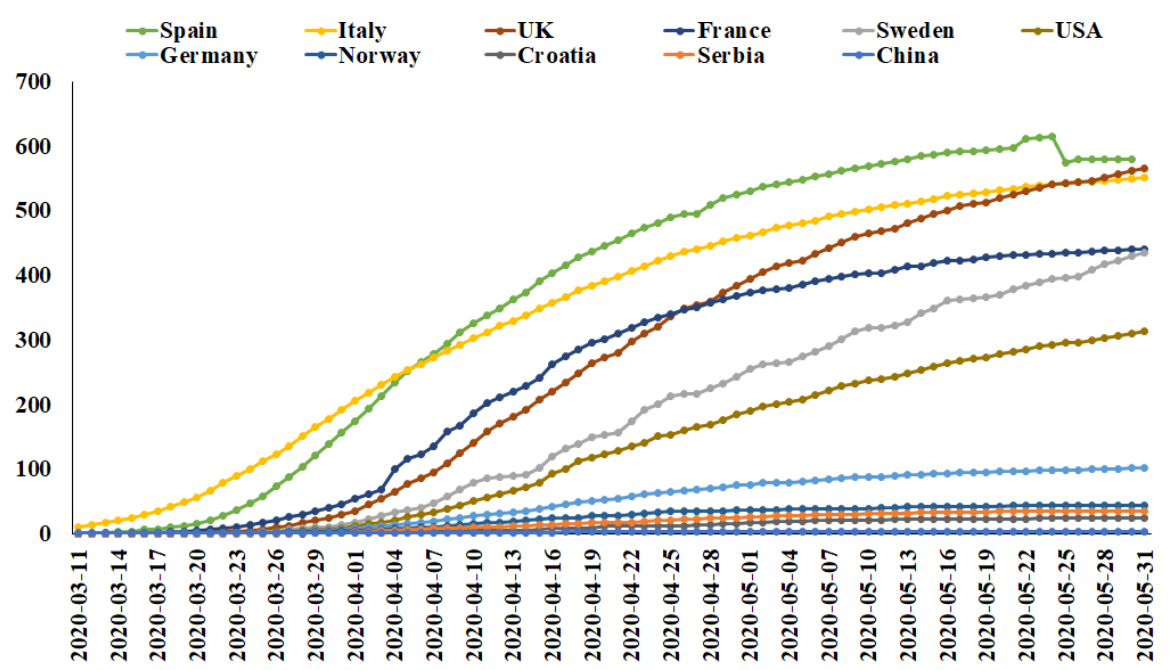

Figure 1: Graph 1. COVID-19 deaths per one million of population for 11 studied states during the period 2020-03-11 to 2020-05-31. The data were taken from the address: https://www.ecdc.europa.eu/en/ publications-data/download-todays-data-geographic-distribution-covid-19-cases-worldwide) [11]. 


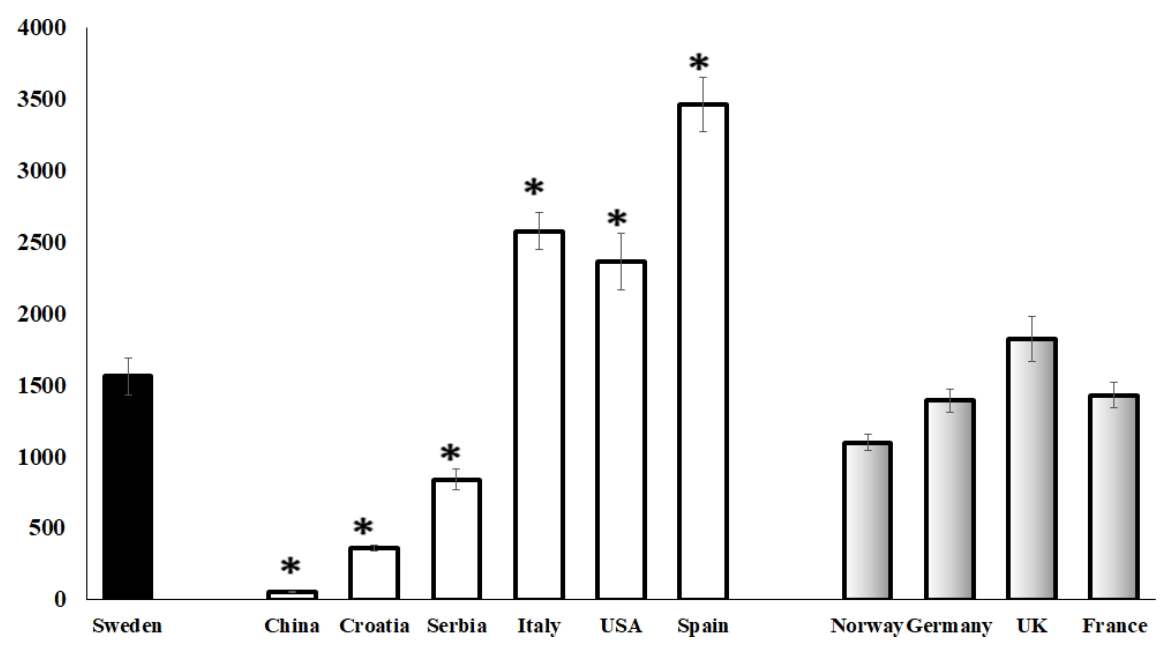

Figure 2: Graph 2. Total cases per one million of population during the period 2020-03-11 to 2020-05-31. The results are presented as mean \pm standard error of the mean. A p value $<0.01$ was considered as significant.

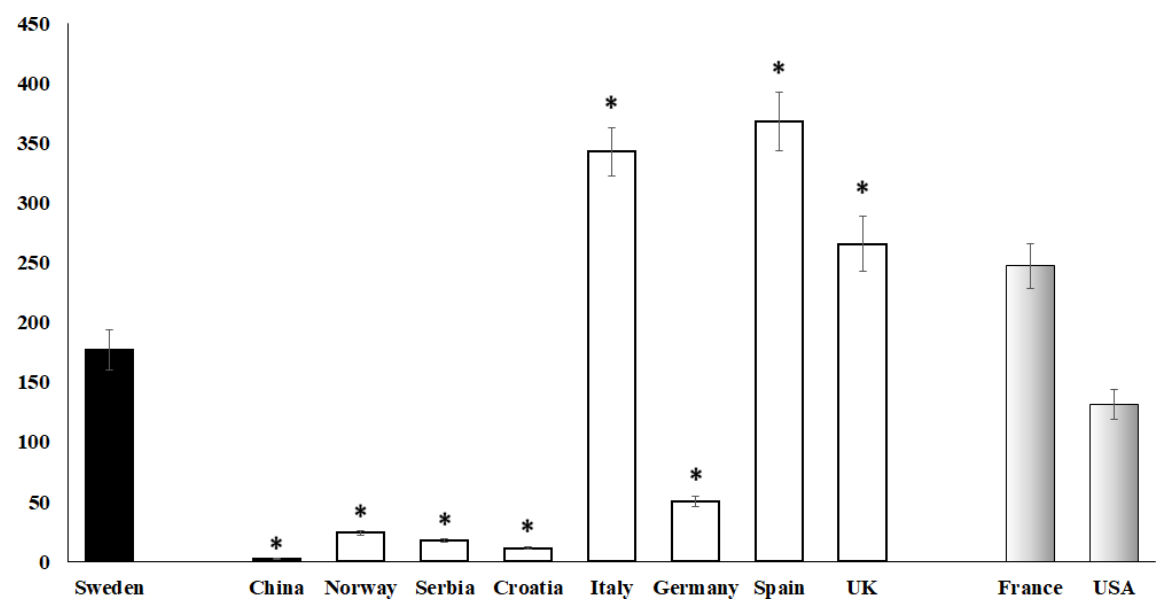

Figure 3: Graph 3. Total deaths per one million of population during the period 2020-03-11 to 2020-0531. The results are presented as mean \pm standard error of the mean. A p value $<0.01$ was considered as significant. 


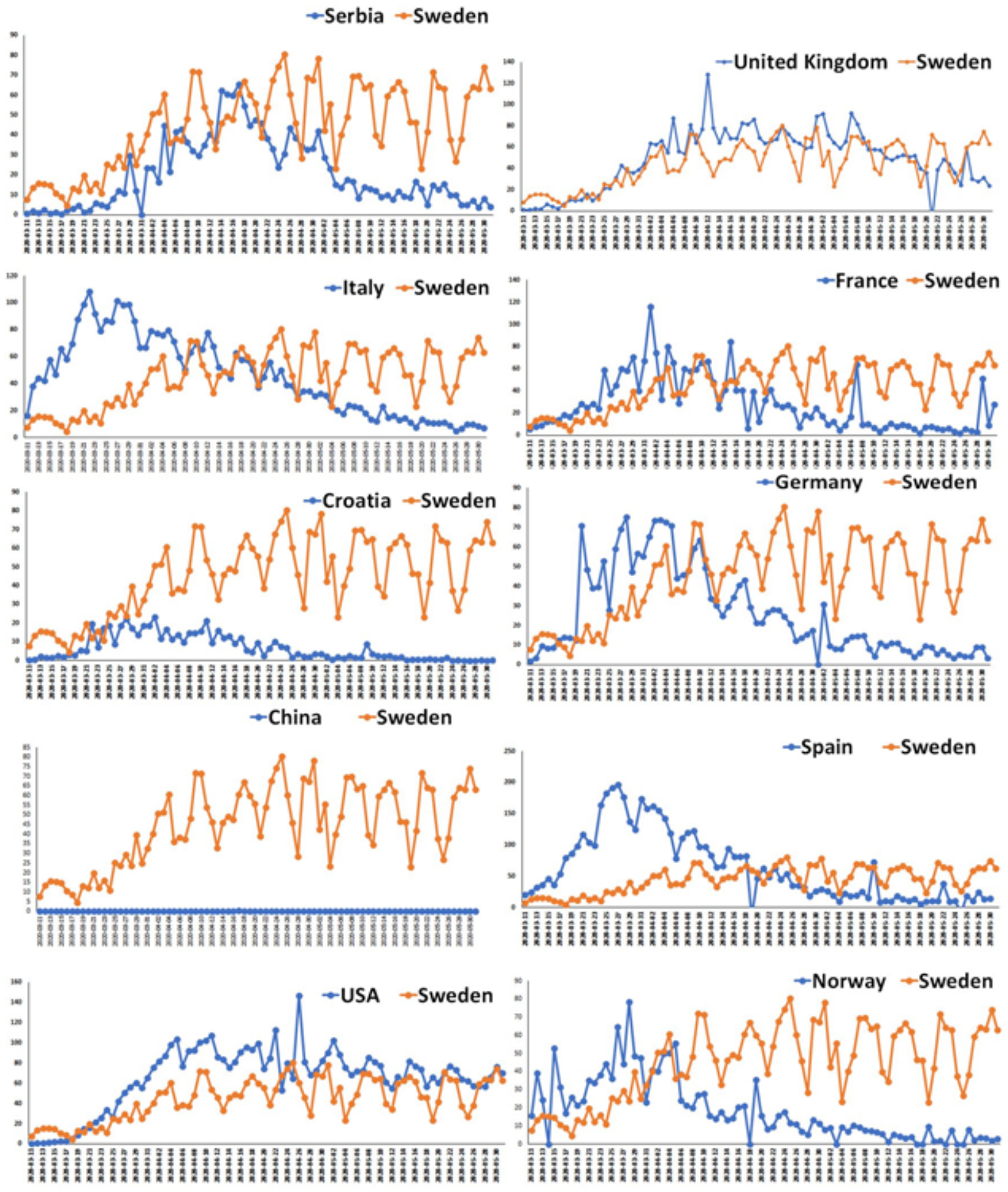

Figure 4: Graph 4. Comparison of new cases per one million of population between studied countries and Sweden. 